\title{
Intergenerational transmission of fertility intentions and behaviour in Germany: the role of contagion
}

\author{
Markus Kotte and Volker Ludwig*
}

\begin{abstract}
This study investigates whether the fertility behaviour of significant others, in particular of one's parents and siblings, affects individuals' own fertility intentions and behaviour. Using the data of three cohorts of young Germans, we test the hypothesis that 'contagion' by siblings with young children explains the transmission of fertility patterns across generations. In theory, transmission might be explained by contagion, or transmission and contagion might operate independently of each other. The results show strong evidence for the transmission of fertility intentions and behaviour from parents to their offspring. Evidence for contagion by siblings is weak and contagious effects therefore do not explain transmission.
\end{abstract}

\section{Introduction}

Fertility patterns are not only determined by individual characteristics, but also by socioeconomic and cultural developments. Interaction in social networks may work as a multiplier of individual and societal factors that have driven the trend towards low and lowest-low fertility (Kohler et al. 2002). Previous research suggests social interaction with members of their family of origin plays an important role when people form preferences about their ideal family size (Axinn et al. 1994; Bühler and Philipov 2005), and when they decide to actually have children (Lyngstad and Prskawetz 2010; Murphy and Knudsen 2002; Murphy and Wang 2001).

A consistent finding in demographic research is that fertility patterns are to some degree transmitted from parents to their children. Transmission effects have

\footnotetext{
${ }^{*}$ Markus Kotte (correspondence author), Munich Center for the Economics of Aging (MEA), Amalienstraße 33,80799 München, Germany. Email: kotte@mea.mpisoc.mpg.de

Volker Ludwig, University of Mannheim, Mannheim Centre for European Social Research (MZES), Germany.
} 
been observed for the age at first birth (Anderton et al. 1987; Barber 2001), but also for the number of (desired and actual) children (Axinn et al. 1994; Booth and Kee 2009; Murphy and Wang 2001; Pullum and Wolf 1991). Another finding of recent studies is that having babies is 'contagious' in the sense that, when an individual's peers conceive, it increases the probability that the individual will also have a child. Contagious effects have been found among neighbours (Bloom et al. 2008) and co-workers (Ciliberto et al. 2010), but also among siblings (Kuziemko 2006; Lyngstad and Prskawetz 2010).

In this study, we evaluated contagion by siblings as an explanation for the intergenerational transmission of fertility intentions and behaviour. We used the data of three cohorts of young Germans born in the early 1970s, 1980s and 1990s from the first two waves of the German Family Panel (pairfam), a large-scale survey that is specifically designed to follow the family planning and birth transitions of individuals during their fertile age. We estimated the effect of parents' fertility, measured as respondents' number of siblings, on respondents' preferred number of children in Wave 2 and on the probability of childbirth or conception from Wave 1 to Wave 2. We further tested whether recent childbirth by a sibling increased a respondent's own desired number of children and the probability of conception.

Our main interest was in determining whether the second effect (contagion) can explain the first effect (transmission), or whether the two effects are independent of each other. Children who grew up in families of greater size may have more children themselves than children from smaller families because they have siblings who may provide access to fertility-related information and support. Alternatively, both phenomena may be driven by distinct underlying mechanisms. In this case, contagion would amplify parental influence on individual fertility. So far, the interplay between transmission and contagion effects has not been fully explored in the literature. Our study is an attempt to fill this gap.

\section{Sibling effects in fertility analysis: theory and evidence}

Existing empirical explanations for the relationship between individual and parental fertility focus on genetic, socioeconomic and cultural factors (see e.g. Murphy and Wang 2001). The fact that children tend to display fertility patterns similar to those of their parents may in part be due to their inherited genetic disposition. However, biological arguments can hardly explain the great variability of fertility patterns across countries and over time. Although recent evidence seems to confirm the view that fertility rates can be partly attributed to genetic predisposition, socioeconomic variables are still important in explaining variation in individual fertility (Kohler et al. 1999; Kohler et al. 2005).

We therefore assume that socioeconomic conditions shape the costs, benefits and expectations that guide conscious fertility decisions; and that this is 
particularly the case in industrialised countries, where the salience of norms guiding sexual behaviour has weakened and contraceptives have become widely available (Kohler et al. 1999). Socioeconomic conditions are dependent on prevailing institutions, policies and macroeconomic trends; and manifest themselves in individual preferences and behaviour. For example, during the transition to market economies, fertility patterns in the former socialist countries of eastern Europe converged rapidly to the low-fertility patterns dominant in western Europe (e.g. Billingsley 2010). Declining fertility levels in eastern Germany after reunification have also been explained by the change in life conditions after the adaptation to western German political and economic institutions (Goldstein and Kreyenfeld 2011).

Recently, researchers have increasingly focused on factors operating at the meso-level of social interactions. Montgomery and Casterline (1996) introduced social learning and social influence as the two main mechanisms through which individual patterns of fertility control are transmitted in social networks. Bongaarts and Watkins (1996) generalised this approach to the analysis of individual fertility. They argued that social learning includes the diffusion of ideas (e.g. values regarding parenting) and knowledge (about, for example, contraceptive methods), as well as the observation of the actions of others to learn about appropriate behaviour (e.g. about how to balance work and family life). In contrast, social influence means that fertility norms are enforced through group pressure and culture. In his theory of planned behaviour, Ajzen (1991) stated that people experience social pressure from their environment to engage in certain kinds of behaviour, which leads to the formation of subjective norms.

Nonetheless, peer contact may also change individuals' life conditions more directly. Bühler and Philipov (2005) followed social capital theory to explain how fertility decisions are shaped by social interactions. They highlighted an important mechanism called the social support explanation. In order to decrease the costs of children, individuals make use of social capital resources, such as information and advice regarding sexual behaviour, contraception and parenting, or monetary and non-monetary support. Access to these resources is granted through interpersonal relationships in networks of social exchange. Because exchange relies on trust and reciprocity, kin relationships can be considered crucial in providing fertilityrelevant resources. Family relationships are typically stable, long-term and close relationships which facilitate the production of trust and the enforcement of the reciprocity norm. Hence, family members not only influence each other regarding childbearing and childrearing behaviour, but support each other in ways that reduce the opportunity costs of children. This line of reasoning is supported by Bühler and Philipov's own empirical analysis, which showed positive effects of substantial support on fertility intentions in Bulgaria. Hank and Kreyenfeld (2003) analysed fertility decisions in eastern and western Germany and found that having access to informal child care significantly increased the probability of childbirth, while availability of public child care did not have any effect. 
We suggest social contagion by siblings as an explanation of transmission. By 'contagion' we mean that contact with peers transitioning to parenthood during one's reproductive phase may increase the desire for children, and, consequently, the probability of conception.

\subsection{Intergenerational transmission of fertility and social contagion by siblings}

Family size preferences presumably are first formed in adolescence, and then are modified throughout adulthood. In adolescence, parents typically educate their children in sexual matters and contraception. Later, parents may advise their adult children in issues of childbearing and parenting. When it comes to actual fertility behaviour, parents may support their children financially, provide cheap housing or offer to assist with child care. As children grow up and become independent of their parents, the power parents have over their children's family preferences may weaken (Axinn et al. 1994). However, parents can be assumed to continue to influence their children's preferences regarding fertility timing and quantum throughout their fertile years. We therefore expect that people will want more children and will be more likely to have children, the larger their family of origin.

Young adults are furthermore influenced by peer groups. Among those peers, siblings play a special role because they belong to the same family of origin. Social contagion by siblings, as defined above, may be based on any of the three mechanisms of learning, influence and support. As Axinn and colleagues (1994) pointed out, "siblings may provide salient behavioural examples" guiding sexual and contraceptive behaviour, fertility decisions and childrearing behaviour. Of course, siblings may also support each other financially or look after each other's children. In addition, having children around the same time may increase the expected benefits of childbirth if peers enjoy sharing common experiences or if they expect that children might profit from contact with a child of similar age (Kuziemko 2006). Furthermore, people may compete with their peers in family formation, and feelings of envy or inferiority may be associated with childlessness (Lyngstad and Prskawetz 2010). The alleviation of psychological strain is, therefore, equivalent to an increase in the expected benefits of childbirth. Thus, narrowly defined, contagion is another social interaction mechanism that may shape the desire for children, and, consequently, fertility behaviour.

To see how social contagion could explain intergenerational transmission, we assume that the fertility of parents and offspring is not causally related. The fertility rate of only children would be identical to the fertility of those with siblings who had no contact with their siblings during their fertile years. However, if contagion by siblings occurred, people who had contact with their siblings would be more likely to have children. Although the true transmission effect is zero in this case, it would nevertheless be possible to observe a positive correlation of parents' and children's fertility without conditioning on siblings' 
fertility. Furthermore, like transmission, contagion predicts a positive relationship between the fertility quantum of parents and children, because a larger number of siblings increases the probability that at least one of the siblings will enter parenthood.

\subsection{Empirical evidence on sibling effects}

Effects of social interaction on childbearing have been found in several studies concerning the content of exchange relationships and network structure (Bongaarts and Watkins 1996; Bloom et al. 2008; Bühler and Philipov 2005; Kohler et al. 2001). However, relatively little research has focused on contagion by peer groups' fertility patterns, and research addressing the interplay of transmission and contagion effects is even more scarce. Several studies have examined sibling effects on the sexual behaviour of adolescents and young adults in order to explain the prevalence of teenage childbirth (see review by Miller et al. 2001). Widmer (1997), for example, analysed the data of 183 cohabiting adolescent siblings, and found that sexual activity among older siblings, particularly among older brothers, significantly decreased the age of first intercourse. These results were obtained after controlling for parental fertility behaviour and attitudes, thus pointing to a sibling effect that seems to be independent of transmission. Lyngstad and Prskawetz (2010) found that a sibling having a child increased the rate of entry into motherhood during the first three years after the birth. For second births, they found that contagion by siblings did not matter. The study also showed a strong interaction effect of siblings' fertility and the age difference of siblings. Contagion effects were found to be stronger the older the sibling was relative to the respondent, and there was no evidence of contagion by younger siblings.

In a similar study, Kuziemko (2006) analysed sibling effects with discretetime hazard models using US data from the Panel Study of Income Dynamics. According to her estimates, the probability of childbirth increased 15 to 17 per cent in the two years after a niece or nephew was born. Interestingly, the findings suggested that contagion may not be limited to the timing of childbirth, because the rate did not drop below the rate of the comparison group after two years. Therefore, contagion by siblings appeared to positively affect both fertility timing and quantum. In this study, contagion was found to be especially strong when siblings were close in age and lived close to the respondent. Contagion was shown to be strongest for poor families, suggesting that cost-saving plays an important role. Support from siblings in the form of advice, child care or goods like toys and clothes was found to lower the expected costs of childbearing. Evidence of contagion by peers was also provided by Ciliberto et al. (2010) who examined the influence of co-workers' childbearing on fertility. In this study, a woman's probability of having a child was shown to increase significantly after her co-workers gave birth. 
Axinn et al. (1994) studied both transmission and contagion by siblings with respect to fertility preferences using the data of 250 families residing in the Detroit metropolitan region. They found that parents' fertility and their preferences regarding family size were passed on to their adolescent children. Moreover, the number of children older siblings had significantly influenced the desired number of children reported by respondents at age 18. However, the analysis focused on family size preferences, not on actual behaviour. In the present study, we examine not only family size preferences, but also respondents' fertility behaviour. Furthermore, like the results of Widmer (1997), the findings of Axinn and colleagues seem to imply that transmission and contagion operate independently of each other. However, neither study specifically addressed the question of whether transmission is nonetheless partially explained by contagion, which is the focus of our empirical analysis.

\section{Data and methods}

This study used data from the first and second waves of the German Family Panel (pairfam), a large-scale panel study on family dynamics. The survey is designed to follow respondents born in 1971-73, 1981-83 and 1991-93 by annual computer-assisted surveys (see Huinink et al. 2011 for further information on design, sampling and survey mode). Our analysis was based mainly on the second wave survey that was carried out from October 2009 to May 2010 with a total of 9,069 respondents. Of these respondents, 39 per cent were in the youngest cohort, 29 per cent in the middle cohort and 32 per cent in the oldest cohort. We excluded the youngest cohort from the analysis of fertility behaviour since childbirth is a very rare event among teenagers in Germany. (Only 13 respondents in this age group reported having a child in Wave 2). A crucial advantage of the second wave of pairfam is that respondents were asked to report on their relationships with members of their network and on the fertility behaviour of these people. In addition, we used data from the first wave (conducted from September 2008 to May 2009; 12,402 respondents) to control for past fertility behaviour and socioeconomic background.

Of the 9,069 Wave 2 participants, 109 were homosexual, and 561 said they (or their partner) were infertile. These respondents were excluded from the analysis. Furthermore, four interviewers who had conducted 10 or more interviews but had recorded less than one network partner on average were identified. We excluded all of the interviews they conducted $(\mathrm{N}=126)$.

In the pairfam network module, respondents were asked to name up to 30 people in their network with whom they frequently met for activities, shared thoughts and feelings or discussed topics they would not discuss with everyone, or occasionally had quarrels or conflicts; or whom they asked for advice in practical matters. The respondents then indicated their relationships to these 
people and (for non-relatives) the social context in which they met. Finally, they provided details about the nature of their relationship with the network partner (emotional closeness, frequency of contact) and about the network partners $\mathrm{him} /$ herself (age, sex, marital status, presence of a partner, relationship to the respondent's partner and parents, and number of children under age three). These questions were not asked about the respondent's partner, parents and children, since this information had already been gathered earlier in the interview. If more than eight persons (not counting the respondent's partner, parents and children) were mentioned, eight were picked at random for this part of the module in order to limit the interview duration. As siblings' fertility was one of our variables of interest, we excluded 78 observations in which at least one sibling had been mentioned as a network person, but had not been randomly chosen for the last questions of the module.

Eliminating cases with missings on any of the independent variables (described below) further reduced the sample size by 374 observations. From the remaining 7,821 observations, we constructed two samples. In order to analyse fertility intentions, we dropped 260 respondents who did not provide information on their preferred family size, which resulted in a sample containing 7,561 observations (83.4 per cent of Wave 2 respondents). The second sample was used to analyse fertility behaviour between Waves 1 and 2 . The youngest cohort was excluded from this analysis $(\mathrm{N}=3,284)$. After dropping 25 interviews that lacked valid information on childbirth and pregnancy after Wave 1, the estimation sample included 4,512 observations ( 81.9 per cent of the two older birth cohorts participating in Wave 2).

Table 1 provides an overview of the means and standard deviations for the main variables used in the two samples to analyse fertility intentions and behaviour. The dependent variable capturing fertility intentions is the number of children respondents would ideally like to have. The wording of the corresponding survey question is: "Assuming ideal circumstances: How many children would you like to have in total?" On average, the preferred number of children in the sample was 2.22 . Fertility behaviour was measured by a dummy variable indicating childbirth between Waves 1 and 2 or pregnancy (of the respondent or his partner) at the time of the Wave 2 interview. In total, 12 per cent of the respondents of the two older cohorts had a child between the waves, or reported that they were expecting a child in Wave 2.

The two independent variables of primary interest were parents' and siblings' fertility. Parental fertility was measured by the number of living brothers and sisters respondents reported in Wave 2. The mean number of siblings was 1.75 and 1.80 for the two samples. In order to examine contagion, we constructed a dummy variable that equals 'one' if a respondent reported at least one sibling as a network partner (with at least one child $<3$ at Wave 2 interview). In the same way, we constructed an indicator for having a friend or other non-relative with a young child. In the first sample including all three pairfam cohorts, four per cent 
of the respondents reported having a sibling with a young child and 18 per cent reported having a friend with a young child. The corresponding figures for the second sample of the two older cohorts were six and 28 per cent.

The pairfam data provide complete information only for those siblings and friends mentioned as network partners, and therefore do not provide complete information on siblings' or friends' fertility. Since close contact is a precondition for contagion, we assumed that this was the correct subset of siblings. Furthermore, we did not have information on the children of network partners born earlier than three years preceding the interview. Consequently, contagion by siblings may be underestimated. However, contagion effects should mainly be based on the recent behaviour of peers (Kuziemko 2006; Lyngstad and Prskawetz 2010).

The other covariates we used in the analysis were the number of biological children born by Wave 1, partnership status, a subjective measure of happiness of childhood, an indicator of the stability of parents' relationship during childhood, and gender and birth cohort. We included partnership status in Wave 1 and the number of children born by Wave 1 because people can be assumed to adapt their preferences to earlier demographic behaviour. Early childhood experiences are included because they are likely to be related to parents' as well as children's fertility. Although we pooled women and men from all of thecohorts for our main analyses (presented in Sections 4.1 and 4.2), we also conducted these analyses based on samples stratified by gender and by birth cohort (Section 4.3). Finally, we used indicators of respondents' level of education, enrolment in the educational system, religious denomination, migration background and residence in eastern Germany as control variables in all our models. For these variables, however, we do not present descriptive results or regression coefficients because they are not central to the argumentation.

First, the bivariate association of respondents' fertility preferences and recent childbearing behaviour with parents' and siblings' fertility was analysed. The two independent variables were then analysed using multivariate regression models. An ordinary least squares regression model was estimated on the respondents' ideal number of children, and a logistic regression model was estimated on the indicator variable for childbirth or conception between waves. In each case, the transmission effect was first estimated by including the number of siblings in the model with control variables. Second, the models were re-estimated, adding dummy variables for siblings' and friends' fertility behaviour. If social contagion by siblings was an explanation of intergenerational transmission, a smaller transmission effect should be observed after controlling for contagion. Furthermore, additional models were estimated separately for the pairfam cohorts, as well as for women and men.

Cross-sectional analyses of peer influence may be subject to endogeneity bias (Manski 1993). The fertility behaviour of siblings and friends might be affected by the behaviour of the respondents. For example, if a respondent gave birth to a 
child between Waves 1 and 2, and also reported having a sibling with a child who was born within the last three years, there is no information on when exactly the sibling's child was born. Thus, it could be the case that the contagion effect operates from the other direction, and that the sibling was 'infected' by the respondent. However, the childbearing of the respondents was considered only between waves; that is, within the last year. Since the siblings' children had been born within the last three years, the problem of reverse causation should have been minimised. In addition, the current pregnancies of respondents or their partners were also taken into account, and those could not have been subject to reverse causation.

Table 1:

Descriptive statistics of main variables of the analysis

\begin{tabular}{lcc|cc}
\hline & Fertility intentions & \multicolumn{2}{c}{$\begin{array}{c}\text { Fertility } \\
\text { behaviour } \\
\text { sample }\end{array}$} \\
\hline Variable & mean & s.d. & mean & s.d. \\
\hline Ideal number of children (Wave 2 information) & 2.22 & 1.01 & 2.29 & 1.09 \\
Newborn child or expecting a child (in Wave 2) & 0.07 & 0.26 & 0.12 & 0.32 \\
Number of siblings (Wave 2) & 1.75 & 1.50 & 1.80 & 1.57 \\
Sibling with child aged <3 yrs. (Wave 2) & 0.04 & 0.20 & 0.06 & 0.24 \\
Friend with child aged <3 yrs. (Wave 2) & 0.18 & 0.38 & 0.28 & 0.45 \\
Female & 0.52 & 0.50 & 0.53 & 0.50 \\
Number of children (Wave 1) & 0.53 & 0.92 & 0.89 & 1.05 \\
Partnership status (Wave 1): Single & 0.45 & 0.50 & 0.24 & 0.43 \\
Living apart together & 0.19 & 0.39 & 0.14 & 0.35 \\
Not married, cohabiting & 0.12 & 0.32 & 0.20 & 0.40 \\
Married, cohabiting & 0.25 & 0.43 & 0.42 & 0.49 \\
Happiness in childhood (Wave 2) & 8.15 & 1.73 & 8.03 & 1.84 \\
(11-point scale, 0=“very unhappy”, 1=“very happy”) & & & & 0.41 \\
Living with both parents until age 18 (Wave 2) & 0.78 & 0.42 & 0.79 & 0.41 \\
Birth cohort 1971-73 & 0.29 & 0.46 & 0.50 & 0.50 \\
Birth cohort 1981-83 & 0.29 & 0.45 & 0.50 & 0.50 \\
Birth cohort 1991-93 & 0.42 & 0.49 & & 4,512 \\
\hline N & 7,561 & & \\
\hline
\end{tabular}

Note: Data of Waves 1 and 2 (conducted 2008/09 and 2009/10) of the German Family Panel (pairfam), data release 2.0. 


\section{Results}

\subsection{Bivariate analysis of transmission and contagion effects}

Figure 1 illustrates the association between the number of siblings and the number of children pairfam respondents said they would like to have under ideal circumstances. Respondents in the cohort of adolescents (aged 15 to 19 at the second wave interview in 2009/10) reported wanting 1.9 children on average if they did not have siblings, but 2.5 children if they had five or more siblings. In the two cohorts of young adults (aged 26 to 29 and 36 to 39 in Wave 2), the mean number of preferred children among respondents without siblings was 2.0, and 2.8 among those with five or more siblings. The overall correlation of the number of siblings and the number of desired children was 0.17 , and was very similar for all three cohorts $(0.16$ for the youngest and the oldest and 0.20 for the middle cohort).

The correlation was not only present in the two older cohorts made up of people in their reproductive phase, but also in the youngest cohort not yet engaged in family planning. Thus, fertility intentions seem to be shaped before people actually have children of their own. From these descriptive results, it is evident that family size preferences are transmitted from parents to adolescents and young adults. Only children want fewer children than those who grew up with siblings. The more siblings people have, the more children they want themselves.

As noted above, social contagion by siblings could explain the correlation across generations. Figure 2 shows that family size preference is indeed linked to the fertility behaviour of one's siblings, at least among respondents of the two older cohorts. These cohorts have sufficiently large numbers of siblings with children (148 and 128 in the middle and older cohorts, compared to only 37 in the youngest cohort). Among respondents in their mid-twenties or mid-thirties, those with siblings and without nieces or nephews below age three reported wanting 2.3 or 2.4 children on average, while those with siblings with young children reported wanting 2.5 or 2.6 children, respectively. The difference of 0.2 children is a bivariate estimate of contagion by siblings, and it is statistically significant at the five per cent level for both cohorts.

Nevertheless, respondents with siblings still expressed a desire for significantly more children than respondents without siblings, even if their siblings did not have young children. The difference was 0.3 in the two younger cohorts and 0.4 in the older cohort. Taken together, the results seem to imply that social contagion might be a partial explanation for the transmission of fertility preferences.

For actual fertility behaviour, the results are less clear. Childbearing or conception between Waves 1 and 2 was associated with the size of the family of origin for respondents in their mid-twenties, but not for the older cohort (see Figure 3). In the cohort born between 1981 and 1983, the proportion of 
respondents who reported having or expecting a child in Wave 2 was 9.6 per cent of those without siblings and 21.3 per cent of those with five or more siblings. In the older cohort, however, there was no evidence of transmission.

Looking at the variation in childbearing conditional on siblings' recent fertility behaviour, no evidence for social contagion was found. Among the respondents who had a sibling with a young child, the proportion who transitioned to parenthood between the waves was slightly smaller, and not, as expected, larger (see Figure 4).

\section{Figure 1:}

Number of children desired by size of family of origin and birth cohort

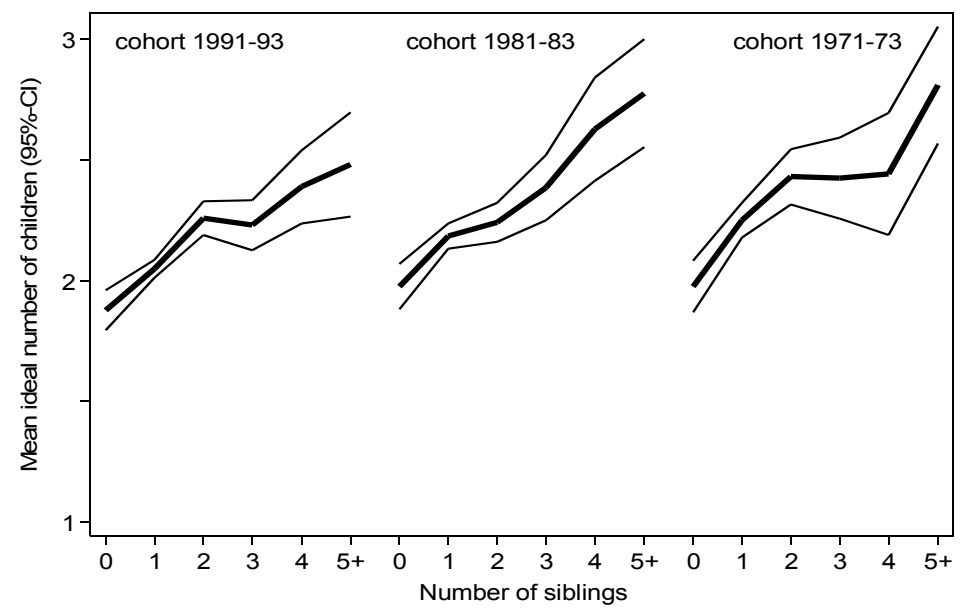

Figure 2:

Number of children desired by fertility of sibship and birth cohort

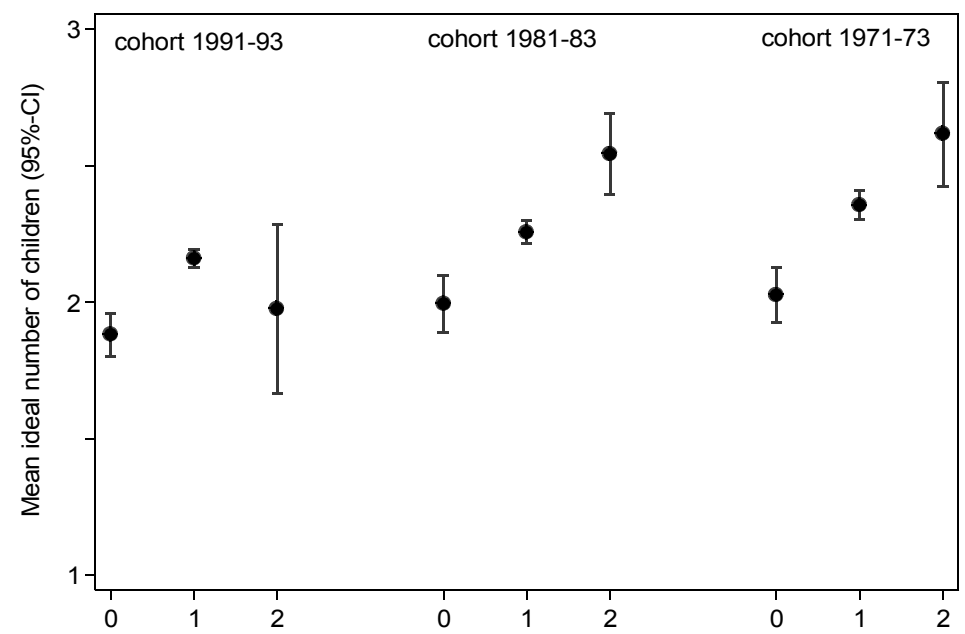

0 : no siblings, 1 : sibling(s) w/o young child(ren), 2: sibling(s) with young child(ren) 
Figure 3:

Recent child birth or conception by size of family of origin and birth cohort

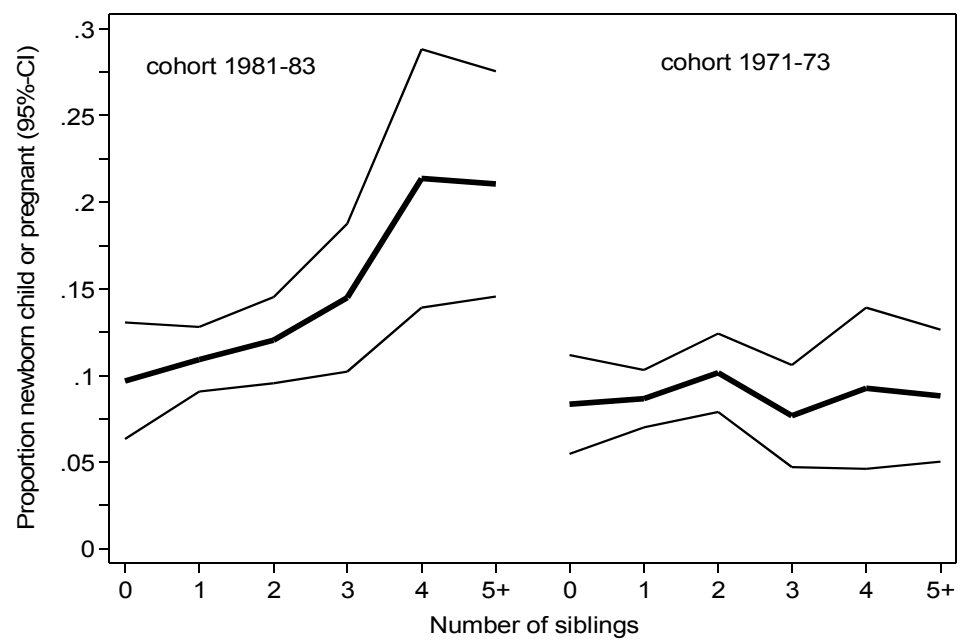

Figure 4:

Recent child birth or conception by fertility of sibship and birth cohort

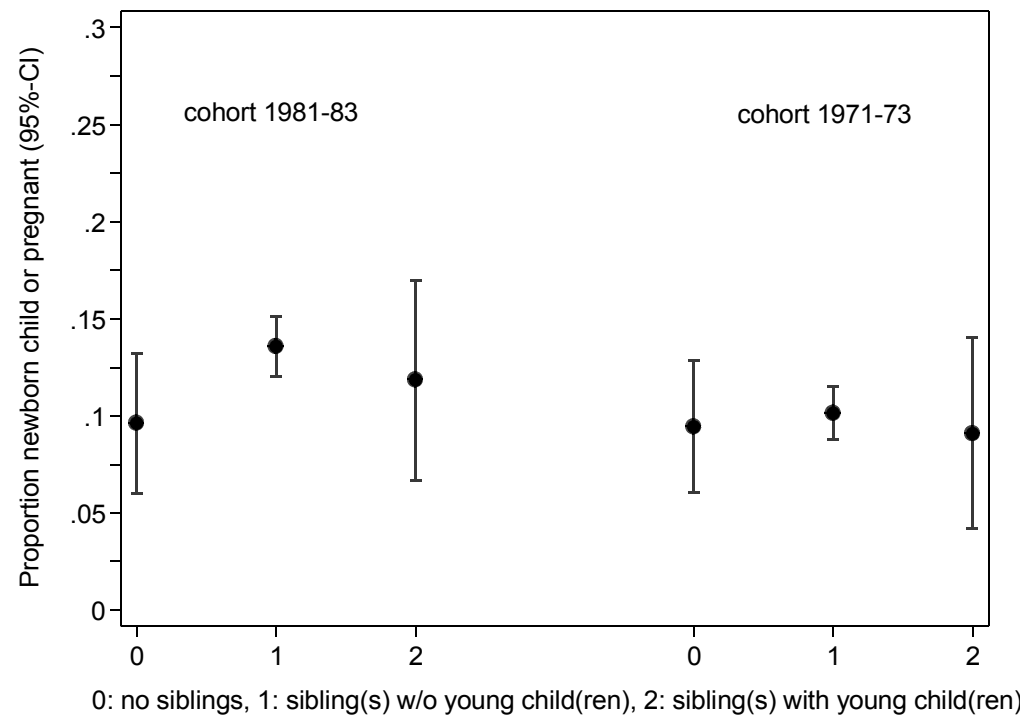




\subsection{Multivariate analysis}

Results from ordinary least squares (OLS) regressions estimating transmission and contagion effects on the ideal number of children are shown in Table 2. The baseline model (column 1) includes the number of siblings, along with controls for demographic and socioeconomic characteristics. The model predicts increasing family size preferences in proportion to the size of the family origin: each sibling increases the desire for children by 0.087 children. Compared to a person who grew up without brothers or sisters, a respondent who grew up with five siblings is expected to want 0.44 more children. Controlling for the demographic and socioeconomic background of respondents therefore does not eliminate the bivariate correlation described in the last section. The regression coefficient obtained without controls was, however, 0.118 , which indicates that at least one-third of the effect was due to background variables. In order to test which variables account for the covariance, the controls were added separately to the bivariate specification and the model was re-estimated. The results show that past fertility, or the number of children born by the time of the Wave 1 interview, accounted completely for the difference in the transmission effect estimated by the bivariate and the full model.

The second model includes two additional regressors to estimate contagion effects: dummy variables for having a sibling with a young child and for having a friend with a young child. The coefficients of both indicators are statistically significant and of similar size. Hence, having contact with people who have recently transitioned to parenthood seems to increase the desire to have children.

However, the contagion effects are rather weak in this model. Having a sibling with a young child is associated with an increase in the preferred number of children by 0.11 children. Contagion by siblings therefore does not explain the transmission of fertility preferences. This is evident from the coefficient for the number of siblings, which remained practically unchanged as siblings' recent fertility behaviour was included in the model (compare Columns 1 and 3). The relatively weak effects resulting from this specification should, however, not be interpreted as indicating that contagion does not matter in family size preferences. In fact, contagion effects can be strong if having children is common in the network. Although the number of respondents with more than one sibling with young children is too small $(\mathrm{N}=18)$ to test this hypothesis, a substantial number of respondents have two or more friends with young children $(\mathrm{N}=381)$. By including the number of friends with young children linearly in the model, a significant effect of 0.064 per friend was obtained (results available from the authors upon request). Contagion may thus travel through the network, and peer influence may become stronger as more contacts are 'infected'. 
Table 2:

Fertility preferences: OLS regression on ideal number of children

\begin{tabular}{lcc|cc}
\hline & Coef. & s.e. & Coef. & s.e. \\
\hline Number of siblings & $0.087^{* *}$ & 0.008 & $0.086^{* *}$ & 0.008 \\
Sibling with child aged $<3$ yrs. & & & $0.108^{*}$ & 0.055 \\
Friend with child aged $<3$ yrs. & & & $0.099^{* *}$ & 0.030 \\
Female & -0.040 & 0.022 & $-0.045^{*}$ & 0.022 \\
Number of children (Wave 1) & $0.460^{* *}$ & 0.018 & $0.460^{* *}$ & 0.018 \\
Partnership (Wave 1) (ref. single): & & & & \\
Living apart together & $0.061^{*}$ & 0.030 & $0.060^{*}$ & 0.030 \\
Not married, cohabiting & 0.030 & 0.041 & 0.028 & 0.041 \\
Married, cohabiting & $-0.087^{*}$ & 0.040 & $-0.096^{*}$ & 0.040 \\
Happiness in childhood & $0.014^{*}$ & 0.007 & $0.014^{*}$ & 0.007 \\
Living with both parents until age 18 & 0.023 & 0.027 & 0.024 & 0.027 \\
Birth cohort 1991-93 (ref. 1971-73) & $0.300^{* *}$ & 0.063 & $0.316^{* *}$ & 0.063 \\
Birth cohort 1981-83 & $0.328^{* *}$ & 0.034 & $0.330^{* *}$ & 0.034 \\
Constant & $0.879 * *$ & 0.134 & $0.854^{* *}$ & 0.134 \\
\hline N & \multicolumn{2}{c|}{7,561} & \multicolumn{2}{c}{7,561} \\
$\mathrm{R}^{2}$ & \multicolumn{2}{c}{0.146} & & \\
\hline
\end{tabular}

Levels of significance: $* \mathrm{p}<0.05 ; * * \mathrm{p}<0.01$.

Note: All models include as further covariates (coefficients not shown): educational level (eight ISCED categories, reference: no educational degree), enrolment in the educational system (ref.: not enrolled), migration background (first-generation immigrant, second-generation immigrant, ref.: no migration background), indicator for living in eastern Germany (ref.: western Germany), religious denomination (Roman Catholic, Protestant, Muslim, other denomination, ref.: no religious denomination).

The results for fertility intentions thus support the view that parents' and siblings' fertility are both factors that explain the variation in family size preferences among the young Germans under study. The interesting question is whether there is evidence of peer influence on actual fertility behaviour. Table 3 presents the results of logistic regression models for estimating the transmission and contagion effects on respondents' probability of childbearing or conception between Waves 1 and 2 of the pairfam study. Estimates of the first model point to a significant effect of parental fertility (Column 1). Controlling for demographic and socioeconomic background, having a brother or sister is associated with an increase in the odds of childbirth or conception of 9.8 per cent. Based on the coefficient, we also calculated effects on the probability (not shown in Table 3 ). Setting all other covariates to the sample mean, the model predicts a probability of 6.7 per cent of having a child for respondents without siblings. The probability 
increases to 10.2 per cent for respondents with five siblings. The marginal effect at the sample mean of 1.8 siblings is 0.67 percentage points. Hence, there is evidence of a transmission effect with respect to fertility behaviour, but the effect is rather weak.

Adding measures of siblings' and friends' childbearing to the model, the probability of childbirth or conception is 29 per cent lower when a sibling (or his/her partner) has given birth to a child within the last three years, but 80 per cent higher if a friend has had a child. Although the negative effect of siblings' fertility is not significant, it clearly is not in line with expectations, while the positive effect of friends' childbearing is. When a respondent's friend is having a baby, the model predicts an increase in the probability of the respondent having a child of 4.6 percentage points. In additional analyses, we replaced the dummy variable of friends' fertility with the linear measure of the number of friends with a young child (results available from the authors upon request). The resulting estimates imply that the probability of childbirth increases from 6.8 per cent for people without such friends to 15.8 per cent for people with five such friends (all other covariates set to the mean). Hence, there is no evidence of contagion by siblings, but strong evidence of contagion by peers outside the family of origin.

\subsection{Differences by cohort and gender}

The finding that fertility intentions are related to siblings' fertility, but that fertility behaviour is not (see Figures 2 and 4), might indicate that fertility preferences do not necessarily translate into actual behaviour. However, preferences and behaviour are clearly related in the data. The correlation of the preferred number of children and the number of biological children born by Wave 2 was 0.24 for the cohort born in the early 1980s and 0.48 for the cohort born in the early 1990s. Moreover, the probability of childbirth or conception between waves was related to fertility preferences reported in Wave 1. Of the middle cohort, 6.8 per cent and 1.9 per cent of the older cohort reported that they did not want children in Wave 1, but nevertheless had or were expecting a child in Wave 2. The corresponding proportions for people who wanted five or more children in the first wave were 21.6 and 9.9 per cent, respectively. In order to explore possible distortions of the average effect of transmission and contagion, the models presented in Tables 2 and 3 were estimated separately by cohort and by gender. Regarding the results for fertility preferences (Table 4a), similar effects of the number of siblings for the two younger cohorts were found. The effect was somewhat smaller for the oldest cohort. The positive effect of siblings' childbearing was similar for the two older cohorts, but was again smaller and insignificant for the oldest cohort. In contrast, the influence of friends' fertility was strongest for the oldest cohort. Although age and cohort effects cannot be clearly separated by cross-sectional comparison, these results are consistent with the view that peer influence within the family of origin declines with age (Axinn 
et al. 1994). At the same time, influence by peers outside the family might increase. Further evidence in support of this hypothesis is shown in Table 4b, but only for transmission. The effect of the number of siblings on actual fertility was smaller for the oldest cohort than for the middle cohort, and it was insignificant. Results for contagion do not, however, fit this hypothesis, as the impact of friends' childbirth was strongest in the middle cohort.

Table 3:

Fertility behaviour: Logistic regression of indicator for newborn child or expecting a child in Wave 2

\begin{tabular}{|c|c|c|c|c|}
\hline & Odds ratio & s.e. & Odds ratio & s.e. \\
\hline Number of siblings & $1.098 * *$ & 0.035 & $1.113 * *$ & 0.035 \\
\hline Sibling with child aged $<3$ yrs. & & & 0.705 & 0.152 \\
\hline Friend with child aged $<3$ yrs. & & & $1.799 * *$ & 0.188 \\
\hline Female & 1.012 & 0.103 & 0.988 & 0.101 \\
\hline Number of children (Wave 1) & $0.542 * *$ & 0.038 & $0.533 * *$ & 0.037 \\
\hline Partnership (Wave 1) (ref. single): & & & & \\
\hline Living apart together & $3.908 * *$ & 1.007 & $3.980 * *$ & 1.028 \\
\hline Not married, cohabiting & $7.749 * *$ & 1.798 & $7.695 * *$ & 1.790 \\
\hline Married, cohabiting & $20.461 * *$ & 4.744 & $20.089 * *$ & 4.672 \\
\hline Happiness in childhood & 1.016 & 0.030 & 1.020 & 0.030 \\
\hline Living with both parents until age 18 & 1.067 & 0.139 & 1.075 & 0.141 \\
\hline Birth cohort 1981-83 (ref. 1971-73) & $1.759 * *$ & 0.209 & $1.806 * *$ & 0.216 \\
\hline Log likelihood & \multicolumn{2}{|c|}{-1406446} & \multicolumn{2}{|c|}{-1389.632} \\
\hline$\chi^{2}(\mathrm{df}=26)$ & \multicolumn{2}{|c|}{407.75} & \multicolumn{2}{|c|}{441.38} \\
\hline McFadden's $\mathrm{R}^{2}$ & \multicolumn{2}{|c|}{0.127} & \multicolumn{2}{|c|}{0.137} \\
\hline $\mathrm{N}$ & \multicolumn{2}{|c|}{4,512} & \multicolumn{2}{|c|}{4,512} \\
\hline
\end{tabular}

Levels of significance: $* \mathrm{p}<0.05 ; * * \mathrm{p}<0.01$.

Note: All models include as further covariates (coefficients not shown): educational level (eight ISCED categories, reference: no educational degree), enrolment in the educational system (ref.: not enrolled), migration background (first-generation immigrant, second-generation immigrant, ref.: no migration background), indicator for living in eastern Germany (ref.: western Germany), religious denomination (Roman Catholic, Protestant, Muslim, other denomination, ref.: no religious denomination).

Comparing the estimates of transmission effects with and without controlling for contagion, there is no evidence of contagion explaining either fertility preferences or fertility behaviour. Contagion by siblings and intergenerational transmission seem to be distinct phenomena that operate independently of each other with respect to fertility preferences. Cohort and gender differences are not 
responsible for the unexpected finding of a negative sibling effect on childbearing behaviour since the effect is negative for both cohorts and for women as well as for men. According to the results, contagion by siblings does not extend to actual fertility behaviour, and thus cannot explain why fertility patterns are passed on by parents to their children.

Table 4:

Transmission and social contagion effects by birth cohort and by gender a. OLS estimates of number of children desired

\begin{tabular}{|c|c|c|c|c|c|c|}
\hline & \multicolumn{2}{|c|}{ Cohort 1991-93 } & \multicolumn{2}{|c|}{ Cohort 1981-83 } & \multicolumn{2}{|c|}{ Cohort 1971-73 } \\
\hline Number of siblings & $0.098 * *$ & $0.099 * *$ & $0.104^{* *}$ & $0.101 * *$ & $0.070 * *$ & $0.068 * *$ \\
\hline Sibling with child $<3$ yrs. & & -0.205 & & $0.180 *$ & & 0.165 \\
\hline Friend with child $<3$ yrs. & & 0.106 & & 0.057 & & $0.131 * *$ \\
\hline \multirow[t]{2}{*}{$\mathrm{N}$} & \multicolumn{2}{|c|}{3,142} & \multicolumn{2}{|c|}{2,202} & \multicolumn{2}{|c|}{2,217} \\
\hline & \multicolumn{3}{|c|}{ Women } & \multicolumn{3}{|c|}{ Men } \\
\hline Number of siblings & $0.061 * *$ & \multicolumn{2}{|c|}{$0.060 * *$} & $0.113 * *$ & \multicolumn{2}{|c|}{$0.112 * *$} \\
\hline Sibling with child $<3$ yrs. & \multicolumn{3}{|c|}{0.117} & & \multicolumn{2}{|c|}{0.115} \\
\hline Friend with child $<3$ yrs. & \multicolumn{3}{|c|}{0.072} & & \multicolumn{2}{|c|}{$0.126 * *$} \\
\hline $\mathrm{N}$ & \multicolumn{3}{|c|}{3,916} & & \multicolumn{2}{|l|}{3,65} \\
\hline
\end{tabular}

b. Logistic regression of indicator for newborn child or conception in Wave 2 (odds ratios)

\begin{tabular}{|c|c|c|c|c|}
\hline \multirow[b]{2}{*}{ Number of siblings } & \multicolumn{2}{|c|}{ Cohort 1981-83 } & \multicolumn{2}{|c|}{ Cohort 1971-73 } \\
\hline & $1.145^{* *}$ & $1.179 * *$ & 1.067 & 1.073 \\
\hline Sibling with child $<3$ yrs. & & $0.558 *$ & & 0.836 \\
\hline Friend with child $<3$ yrs. & & $1.759 * *$ & & $1.518^{* *}$ \\
\hline \multirow[t]{2}{*}{$\mathrm{N}$} & \multicolumn{2}{|c|}{2,270} & \multicolumn{2}{|c|}{2,242} \\
\hline & \multicolumn{2}{|c|}{ Women } & \multicolumn{2}{|c|}{ Men } \\
\hline Number of siblings & $1.129 * *$ & $1.146^{* *}$ & 1.055 & 1.069 \\
\hline Sibling with child $<3$ yrs. & & 0.772 & & 0.601 \\
\hline Friend with child $<3$ yrs. & & $1.951 * *$ & & $1.553^{* *}$ \\
\hline $\mathrm{N}$ & \multicolumn{2}{|c|}{2,392} & \multicolumn{2}{|c|}{2,120} \\
\hline
\end{tabular}

Levels of significance: ${ }^{*} \mathrm{p}<0.05 ; * * \mathrm{p}<0.01$.

Note: Estimates for number of children desired (Panel a) were obtained using the specifications of the models shown in Table 2. Estimates for childbirth (Panel b) are based on specifications of the models shown in Table 3. 


\section{Conclusion}

This study examined the intergenerational transmission and social contagion effects on the fertility intentions and fertility behaviour of teenagers and young adults in their mid-twenties and mid-thirties using data from the first two waves of the German Family Panel (pairfam). In particular, the hypothesis that contagion by siblings can explain the positive association between parents' and their children's fertility was developed and tested.

Consistent with earlier research (Axinn et al. 1994; Booth and Kee 2009; Murphy and Wang 2001; Pullum and Wolf 1991), the results showed that fertility preferences and behaviour are indeed passed on from one generation to the next. The more siblings respondents had, the more children they desired and the more likely they were to have actually had a child in the one-year interval between interviews, or to have been expecting a child at the time of the second interview. Evidence of peer influence from outside the family of origin was also found. Having a friend or other non-relative who had given birth to a child within the last three years was associated with stronger preferences for children and with a higher probability of childbearing.

However, evidence for contagion by siblings was weak with regard to family size preferences, and nonexistent in the analysis of actual fertility behaviour. In fact, respondents who reported having a young niece or nephew were less likely to have had a newborn or to have been expecting a child in Wave 2 (though the effect was not significant). Consequently, contagion by siblings could not explain the higher fertility rate of young Germans who grew up in large families, compared to those from small families. Therefore, while social interaction with parents and friends may work as a multiplier of individual and macro-level factors determining fertility rates (Kohler et al. 2002), interaction with siblings does not.

The finding of a negative effect of siblings' childbearing on fertility behaviour is not consistent with earlier longitudinal studies that show positive effects (Lyngstad and Prskawetz 2010; Kuziemko 2006), and this might be due to the limitations of the data we used. The analysis was based on the assumption that contagion would have been caused only by the people named by the respondents as network partners; that is, people with whom they meet for activities, share thoughts and feelings, or have quarrels or conflicts; or whom they ask for advice or information. It may be the case that the network generated by these survey questions missed relationships that are relevant for fertility decisions. Moreover, information on the childbearing of siblings who were not mentioned as network partners was not available. These restrictions introduced measurement error, and might therefore have biased the estimates of contagion effects downwards. However, the finding of strong contagion effects by friends seems to indicate that the quality of the data is sufficient to study peer effects on fertility.

Another limitation of this study is that it is based on cross-sectional methods, and might therefore be subject to endogeneity bias. The problem of reverse 
causation (Manski 1993) of ego's and alter's fertility should have been minimised because the peers' childbearing in most cases occurred earlier than ego's conception. Based on the data used, it cannot be ruled out, however, that endogeneity introduced some bias. In addition, peer effects might also have been biased by the selectivity of the network if ego chose his/her peer contacts according to his/her fertility preferences. That is, at the time ego started to engage in family planning, he/she may have sought out friends who already had children, and this might have produced a spurious correlation between their fertility behaviour observed later on.

Nevertheless, as the pairfam study will continue and information on fertility of network persons will be available at several stages of the life-course, it should be possible to overcome most of these limitations. Moreover, it should become possible to distinguish between sibling effects on fertility timing and quantum. Finally, the approach of separating transmission effects and contagion by siblings might be applied to other demographic behaviours as well, such as to marital stability (McDermott et al. 2009).

\section{References}

Ajzen, I. 1991. The Theory of Planned Behavior. Organizational Behavior and Human Decision Processes 50: 179-211.

Anderton, D.L., N.O. Tsuya, L.L. Bean and G.P. Mineau 1987. Intergenerational transmission of relative fertility and life course patterns. Demography 24(4): 467-480.

Axinn, W.G., M.E. Clarkberg and A. Thornton 1994. Family influences on family size preferences. Demography 31(1): 65-79.

Barber, J.S. 2001. The intergenerational transmission of age at first birth among married and unmarried men and women. Social Science Research 30: 219-247.

Billingsley, S. 2010. The post-communist fertility puzzle. Population Research and Policy Review 29(2): 193-231.

Bloom, D.E., D. Canning, I. Günter and S. Linnemayr 2008. Social interactions and fertility in developing countries. Harvard School of Public Health: Working Paper 34.

Bongaarts, J. and S.C. Watkins 1996. Social interactions and contemporary fertility transitions. Population and Development Review 22(4): 639-682.

Booth, A.L. and H.J. Kee 2009. Intergenerational transmission of fertility patterns. Oxford Bulletin of Economics and Statistics 71: 183-208.

Bühler, C. and D. Philipov 2005. Social capital related to fertility: theoretical foundation and empirical evidence for Bulgaria. Vienna Yearbook of Population Research. Vol. 3: 53-81.

Ciliberto, F.A.R. Miller, H.S. Nielsen and M. Simonsen 2010. Playing the fertility game at work. University of Virginia: mimeo.

Goldstein, J.R. and M. Kreyenfeld 2011. Has East Germany overtaken West Germany? Recent trends in order-specific fertility. Population and Development Review 37: 453-472. 
Hank, K. and M. Kreyenfeld 2003. A multilevel analysis of child care and women's fertility decisions in Western Germany. Journal of Marriage and Family 65(3): 584-596.

Huinink, J., J. Brüderl, B. Nauck, S. Walper, L. Castiglioni and M. Feldhaus 2011. Panel analysis of intimate relationships and family dynamics (Pairfam) - conceptual framework and design. Journal of Family Research 23(1): 77-100.

Kohler, H.-P., J.R. Behrman, S.C. Watkins 2001. The density of social networks and fertility decisions: evidence from South Nyanza district, Kenya. Demography 38(1): 43-58.

Kohler, H.-P., F.C. Billari and J.A. Ortega 2002. The emergence of lowest-low fertility in Europe during the 1990s. Population and Development Review 28: 641-680.

Kohler, H.-P., J.L. Rodgers and K. Christensen 1999. Is fertility behavior in our genes: findings from a Danish twin study. Population and Development Review 25: 253-88.

Kohler, H.-P., J.L. Rodgers, W.B. Miller, A. Skytthe, K. Christensen 2005. Bio-social determinants of fertility. International Journal of Andrology 29:46-53.

Kuziemko, I. 2006. Is having babies contagious? Estimating fertility peer effects between siblings. Mimeo, Harvard University.

Lyngstad, T.H. and A. Prskawetz 2010. Do siblings' fertility decisions influence each other? Demography 47(3): 923-934.

Manski, C. 1993. Identification of endogenous social effects: the reflection problem. Review of Economic Studies 60(3): 531-542.

McDermott, R., J.H. Fowler and N.A. Christakis 2009. Breaking up is hard to do, unless everyone else is doing it too: social network effects on divorce in a longitudinal sample followed for 32 years. Mimeo.

Miller, B.C., B. Benson, K.A. Galbraith 2001. Family relationships and adolescent pregnancy risk: a research synthesis. Developmental Review 21: 1-38.

Montgomery, M.R. and J.B. Casterline 1996. Social learning, social influence, and new models of fertility. Population and Development Review 22: 151-175.

Murphy, M. and L.B. Knudsen 2002. The intergenerational transmission of fertility in contemporary Denmark: the effects of number of siblings (full and half), birth order, and whether male or female. Population Studies 56(3): 235-248.

Murphy, M. and D. Wang 2001. Family-level continuities in childbearing in low-fertility societies. European Journal of Population 17: 75-96.

Pullum, T.W. and D.A. Wolf 1991. Correlations between frequencies of kin. Demography 28(3): 391-409.

Widmer, E.D. 1997. Influence of older siblings on initiation of sexual intercourse. Journal of Marriage and the Family 59: 928-938. 